\title{
Barriers to Engaging Rural Latino Immigrant Communities in Substance Use Research
}

\author{
Katheryn Rodriguez $\circledast^{1}$, Christine Newkirk², Agustin Maximo Anastacio ${ }^{3}$, \\ and Ann M. Cheney(0) ${ }^{4}$ \\ ${ }^{1}$ Center for Health Disparities Research, University of California, Riverside, CA \\ ${ }^{2}$ The Center for Nonprofit Management, Los Angeles, CA \\ ${ }^{3}$ Riverside City College, Riverside, $C A$ \\ ${ }^{4}$ Department of Social Medicine \& Population Health, School of Medicine, University of California, \\ Riverside, $C A$
}

\begin{abstract}
Background and Purpose: In this paper, we report on the barriers to engaging rural Latino immigrants in community-engaged research on substance use. There is an urgent need to engage this population, who are at risk for substance use and abuse, in research to reduce health disparities. Methods: Our work involved ethnographic unstructured interviews $(\mathrm{n}=18)$, a one-time Community Advisory Board, and focus groups $(\mathrm{n}=3)$ with 52 participants in southern California's Coachella Valley. Results: Through an inductive analysis, we found culture, geography, and social status intersect with community-level factors (e.g., poor infrastructure) in creating barriers preventing Latino immigrants from engaging in substance use research. Conclusions: These findings show that one way to effectively address the needs of rural Latino immigrants is for researchers to develop collaborative partnerships with communities. Developing strong relationships between institutions and vulnerable populations can move us one step closer to alleviating health disparities.
\end{abstract}

(C) 2020 and CC-BY 4.0 licensed by the authors.

Keywords: community engaged research; farmworkers; gender; Latino immigrants; rural health; machismo

\section{Introduction}

Collaborative partnerships between communities and academic researchers (Tapp, White, Steuerwald, \& Dulin, 2013) allow a community to participate in the planning, design, and implementation of research studies (Ganann, 2013). Furthermore, community-based research (CBR) is an effective approach to develop, deliver, and evaluate interventions aimed at reducing health disparities in underserved communities (Israel, Schulz, Parker, \& Becker, 1998). Some populations, such as immigrant and minority populations, are underrepresented in health disparities research (Deren, Shedlin, Decena, \& Mino, 2005). Barriers for these groups include: structural inequalities and social injustices (e.g., racism, underrepresentation) (Olson, Cottoms, \& Sullivan, 2015; George,

Duran, \& Norris, 2014; Hussain-Gambles, Atkin, \& Leese, 2004) as well as researcher bias (Sheikh, Halani, Bhopal, \& Car, 2009), ineffective recruitment strategies (UyBico, Pavel, \& Gross, 2007), and limited or absent researcher knowledge of culturally based communication and social norms (Williams, Mohammed, Leavell, \& Collins, 2010). Immigrant and minority participants may also fear or mistrust research and researchers (Corbie-Smith, Thomas, \& St George, 2002), believe all research is inherently intrusive and potentially harmful (Hinton, Guo, Hillygus, \& Levkoff, 2000), or fear deportation if their immigration status is recorded (Katigbak, Foley, 
Robert, \& Hutchinson, 2016; Calderón et al., 2006).

While these factors create challenges for researchers attempting to form collaborative research partnerships with immigrant and minority persons, the research topic itself may add an additional barrier to engagement. Multiple studies have shown the challenges of engaging immigrant and minority populations in substance use and related sexual risk research (Waheed, Hughes-Morley, Woodham, Allen, \& Bower, 2015; Alvarez, Vasquez, Mayorga, Feaster, \& Mitrani, 2006; Lopez, 2002). As engaging Latinos in this area of research is especially challenging (Amaro, Cortes, \& Cacari-Stone, 2006), it represents an area for improvement.

Latinos, particularly male Latino immigrants in rural areas, are at heightened risk for substance use and abuse (Negi, 2011; Valdez et al. 2010). For Latino immigrants, context-specific norms around sexual behaviors (e.g., paying for sex), mobile lifestyles, physical work demands of manual labor, and increased access to alcohol and drugs can make them especially susceptible to substance abuse (Hernandez, Donovan, Grinberg, Obenaus, \& Carson, 2016; Valverde et al., 2015; Apostolopoulos et al., 2006). The potential consequences of this risk may be greater for Latino immigrants in rural communities where there are few healthcare services and opportunities for prevention and treatment (Chen, Gallant, \& Page, 2012; de Jesus Diaz-Perez, Farley, \& Cabanis, 2004). The rural Latino population compromises a "majority minority" in many rural and small towns across the US (The Housing Assistance Council, 2012). Approximately 6 million Latinos live in rural areas of the US; the majority work in agriculture (Saenz, 2008). Geographic isolation, low income, undocumented legal status, low English proficiency, and limited access to healthcare services contribute to Latino farmworkers' vulnerability to poor health outcomes (National Center for Farmworker Health, 2017; London,
Greenfield, \& Zagofsky, 2013; Albarrán \& Nyamathi, 2011; Hansen \& Donohoe, 2003).

The analysis presented in this paper is from a larger study that reports on the structures and chronic daily strains that create stress for Latino immigrants in rural borderland communities, which negatively affect their mental and physical health (Cheney et al., 2018). Our work is framed within a critical public health perspective, and we incorporate intersectionality to highlight the negative impact of structural factors, specifically violence created via social interaction and institutional practices present on the streets and in the fields and homes of those effected by the inequalities, on Latino immigrants' civic engagement, specifically engagement in health research (Bourgois \& Hart, 2011; Holmes, 2011; Quesada, Hart, \& Bourgois, 2011).

An intersectional approach therefore may be best able to address this gap and ameliorate the barriers; additionally, substance use patterns among Latino immigrant populations suggest a need to engage this community through the evolution of research and policy. The underlying structure of differences in patterns, particularly among immigrants, calls for an intersectional approach to possible solutions. As an overarching concept, the examination of intersectionality in the study of these populations could serve as a tool to shape future relevant research. Drawing on gender, positionality, and the geographic space, we aim to understand both anticipated barriers to engaging with minorities in substance use research and possible approaches when working with these communities.

\section{Methods}

This research involved several steps and methods and began with ethnographic work (observations, informal and unstructured interviews), followed by a one-time Community Review Board to obtain feedback on study design, and focus groups. We continuously updated the research design and study questions 
based on community input using a community based participatory research (CBPR) framework, which encourages collaborative partnerships and allows for meaningful community involvement and input on local health disparities (Burke \& Albert, 2014; Minkler \& Wallerstein, 2008). The initial study team included an anthropologist with expertise in substance use and mental health services research, an expert in Latino community engagement, and a bicultural Latina student.

\section{Study Design}

Our ethnographic work made us aware of the sensitive nature of the research topic and the challenges of engaging Latino farmworkers in CBPR on health disparities. Consequently, with the support of local community leaders, we organized a one-time Community Review Board, a method developed by Vanderbilt's Clinical Translational Research Award (Vanderbilt University Medical Center, 2017), to obtain meaningful community input on the development of our study. The Community Review Board of nine participants, including a male farm worker, farmworker advocates $(n=2)$, local community college students $(\mathrm{n}=2)$, a youth organizer $(n=1)$, and service providers $(n=3)$, provided a venue for community experts to: share their thoughts on the research topic; discuss the relevance of the work to Latino farm working communities; and contribute input on research questions, study design, and recruitment strategies. All participants were Latino and all but one grew-up in the ECV in a farm working family. The CRB provided feedback on research questions, sample and recruitment strategies, participant remuneration, and cultural and ethical considerations. During the conversation, participants suggested we conduct focus groups with both men and women living in farm working communities to provide a comfortable space to facilitate the conversation and mentioned the importance of adding a male member in the team. They also suggested the interview guide transition from general topics to community health concerns to sensitive and potentially uncomfortable health topics, including alcohol and drug use and related risk behaviors.

As the study progressed, a male Latino immigrant was added to the research team; the team was expanded so we could connect with male participants (explained below). We collaborated on the design and implementation of the study with a non-profit farmworker advocacy organization, service providers, and community leaders. For the purposes of this paper, we conducted a secondary analysis of the dataset to better understand barriers to engaging this community as this theme emerged in the process of data collection. That said, this analysis presented in this paper asks questions that were not initially part of the original study. This is an emerging trend in qualitative research and marks a significant shift in the conventional use of qualitative datasets; from analyses intended to answer the original research questions to additional analyses intended to answer new research questions (Tate, Devito Dabbs, Hoffman, Milbrandt, \& Happ, 2012; Fielding, 2004).

\section{Setting}

This study was conducted during 2015 - 2016 in the Eastern Coachella Valley (ECV). The Coachella Valley is often divided into two geographic regions. The ECV is largely comprised of Mexican-origin agricultural families living well below the poverty line (Colletti, Smith, Herrera, Herrera, \& Flores, 2006), and stands in stark contrast with more affluent cities in the western part of the valley with a majority of middle-to-upper class Americans. The ECV includes one small town and four unincorporated communities and is home to over 100,000 acres of agricultural land. Based on seasonal migration patterns, the population of the ECV includes between 3,000 to 10,000 farmworkers (Colletti et al., 2006). Approximately $14 \%$ of residents in the ECV are undocumented, $95 \%$ of whom are from Mexico (Marcelli \& Pastor, 2015). 
Agricultural business infrastructure has been built around a history of farm laborer exploitation since the early $20^{\text {th }}$ century (DuBry, 2007). Latinos have been significantly marginalized by the lasting effects of the Bracero labor program implemented in 1942 (Bickerton, 2001). Despite the large contribution of farmworkers to the economy, the braceros suffered all types of abuses, including violation of the original stipulations of the agreement in regards to housing, health, wages, and working hours and numerous cases of discrimination, particularly in farms in the state of California (Cohen, 2011). Farmworker unionization and resistance began in the 1930s and continues to be part of Latino farmworkers' experience (Mitchell, 2007). Grassroots activism in the ECV honors the history of the braceros by advocating for the protection of farmworkers (Blackwell, 2006).

\section{Procedures Ethnographic Methods.}

During the initial stages of the study, trained study team members made observations and conducted informal (i.e., natural conversation) and unstructured (i.e., non-directive) interviews with community leaders, community advocates, students, and healthcare service providers to begin to understand substance use among Latinos in the ECV (Bernard, 2002). Observations and interviews took place in public offices, clinics, restaurants, trailer parks, homes, and campus settings. Key points and observations were jotted down in notebooks and entered into a Word document after each conversation/interview.

Samples Focus Groups. Based on CRB feedback, we conducted focus groups with members of farm working communities regarding the larger context of substance use in the ECV. We recruited participants (farmworkers, farmworker advocates, and members of farm working families in the ECV) with collaboration of a non-profit farmworker advocacy organization and the CRB. We conducted a total of three researcher-led focus groups: one male-led with male farmworkers and two female-led with female farmworkers and/or farmworker advocates. All focus groups were conducted in Spanish. The number of participants per focus group varied, ranging from two to 12, with an average of 8 . Focus groups were held in public venues (i.e., a church, a conference center, and a public office), audio recorded, and lasted $\sim 85$ minutes (ranging from 75 to 120 minutes). Participants received $\$ 50$ (plus \$20 travel reimbursement). All focus groups were professionally transcribed. Quotes were translated from Spanish to English by a native bilingual and bicultural speaker.

\section{Data Collection}

We designed the interview guide to transition from general topics to sensitive and potentially uncomfortable health topics to facilitate discussion of alcohol and drug use, sexual relationships, and sex and HIV risk behaviorsan approach Community Review Board participants encouraged. The Spanish-speaking facilitators used a semi-structured interview guide with open-ended questions to elicit general information on the day-to-day life of farmworkers in the ECV, common struggles (e.g., financial or family problems), and community health concerns, followed by specific information on substance use and sexual behaviors (e.g., paying for sex) and risk for sexually transmitted infections and HIV/AIDS.

\section{Data Analyses}

We used an inductive approach to analyze the data and develop grounded hypotheses (Kearney, Murphy, Irwin, \& Rosenbaum, 1995). All Word documents and transcripts were imported into MAXQDA, a qualitative data analysis software program (Verbi SoftwareConsult, 2016), and data were coded and analyzed. Team members used open coding (line-by-line reading of the text) to identify emergent themes and develop an initial codebook (H. Russell Bernard \& Gery Wayne Ryan, 2010; H. R. Bernard \& G. W. Ryan, 2010). During this stage of analysis, team members independently applied the coding schema to the same transcripts to assess inter- 
coder agreement (MacQueen, McLellan, Kay, \& Milstein, 1998). Codes and their application were discussed, and the codebook revised until group consensus was reached. Team members used in vivo coding to apply codes to all Word documents and transcripts. Finally, axial coding (i.e., constant comparison) was used to examine relationships between themes and across participants' discussions and to develop a story line and conceptual model grounded in the data (Corbin \& Strauss, 2015).

\section{Results}

\section{Focus Group Participant Characteristics.}

As outlined in Table 1, all participants identified themselves as Latino of Mexican origin $(100 \%$, $\mathrm{n}=25)$. Participants' ages ranged from 21-85 years (average $=43$ ). Most of the participants had children (86\%), while $40 \%$ were married; $60 \%$ of participants rented, from which $48 \%$ lived in local trailer parks. The majority $(84 \%)$ of the participants were monolingual Spanish speakers, $12 \%$ were bilingual Spanish and English, and $8 \%$ were bilingual Spanish and Purépecha (an indigenous group from the Mexican state of Michoacán). More than two-thirds of participants did not complete a high school education $(71 \%)$, and over half (52\%) worked in the fields.

\section{Barriers to Research Engagement}

Our analysis highlighted the intersection of gender role expectations (e.g., machismo), geography, and social status with community level factors (e.g., poor infrastructure) to create barriers for Latino immigrants to engage in substance use research.

Gender Role Expectations as Barriers to Engagement. Participants often discussed gender role expectations as barriers to engaging the community in research on substance use. Community organizations that worked directly with farmworkers were well aware of the barriers gender could play when engaging men in research. During the Community Review Board, participants pointed out that having a research team composed of women was a substantial barrier to engaging men in research. One participant said: "If a woman is going to be the one coming and asking questions, then I think it would be better if she has the help of a male, and he has to be a Latino."

Table 1.

Demographics and Characteristics of Participants $(\mathrm{n}=25)$

\begin{tabular}{|c|c|}
\hline Characteristics & $\%$ \\
\hline \multicolumn{2}{|l|}{ Ethnicity } \\
\hline Latino/Hispanic-American & 100 \\
\hline Indigenous origin & 8 \\
\hline \multicolumn{2}{|l|}{ Age } \\
\hline $21-30$ & 12 \\
\hline $31-40$ & 24 \\
\hline $41-59$ & 52 \\
\hline $60+$ & 12 \\
\hline \multicolumn{2}{|l|}{ Marital Status } \\
\hline Single & 8 \\
\hline Married & 40 \\
\hline Widowed, Separated, Divorced & 36 \\
\hline \multicolumn{2}{|l|}{ Have Children } \\
\hline $1-2$ or more children & 32 \\
\hline 3 children & 16 \\
\hline 3 or more children & 40 \\
\hline Declined to answer & 12 \\
\hline \multicolumn{2}{|l|}{ Education } \\
\hline High school non-completion & 71 \\
\hline \multicolumn{2}{|l|}{ Field work } \\
\hline Work in the field & 52 \\
\hline Do not migrate or change routes* & 20 \\
\hline \multicolumn{2}{|l|}{ Housing } \\
\hline Rent & 60 \\
\hline Live in trailer parks & 48 \\
\hline \multicolumn{2}{|l|}{ Language } \\
\hline Spanish & 84 \\
\hline Bilingual Spanish-English & 12 \\
\hline Bilingual Spanish-Purépecha & 4 \\
\hline
\end{tabular}

Focus group participants also brought up specific challenges of an all-female study team conducting substance use research that included questions on sexual risk and HIV/AIDS with Latino men. One woman said: "It's going to be difficult for them to talk to you, we were raised differently, and it is another culture, es machismo." When asked for a definition of machismo, one woman explained, "That word is 
used to describe the boss in the house, el león de la selva [the lion in the jungle]."

Focus group participants stated gender defined the appropriate topics of discussion, whether men or women could discuss the issues and with whom, and acceptable behaviors. We observed this in the all-male focus group, led by a male Latino immigrant recruited specifically for this group interview. Prior to starting the focus group and during the introduction of the research and consent process, one participant left the room. He appeared nervous as soon as the topic of health, specifically substance use and sexual health, was raised. After he left the room, another participant, who had recruited the man to the focus group, commented:

One time he told me that he had a disease, he did not tell me exactly what it was but I knew about it. I think that is why he decided to leave because he realized that we were going to talk about STDs and that is probably what he has.

We observed similar situations in which gender, specifically men in relationship to machismo, influenced study participation given the sensitivity and sexual nature of the research topic (i.e., substance use and sexual transmitted disease risk). One man explained,

When I realized it was a conversation about AIDS, sex, and all that stuff I was surprised ... sometimes you can't say things the same [to a woman] as you would de hombre a hombre (man to man). It depends on your way of thinking.

We noticed indirect communication and lack of eye contact during conversations between female researchers and male farmworkers; initially during a conversation in which a female researcher guided the conversation, and the participant directed his responses to the male researcher. This style of communication carried through to the men's focus group; male farmworkers did not respond or communicate directly with the female researcher (who remained in the room only to obtain participants' written consent).

Machismo was not only a barrier for men, but influenced women's involvement in the research. During a focus group, one woman commented:

Yeah he [her husband] just wants to control me. I can't tell him, 'Hey I am going to have a meeting and we are going to talk about this [sex]!' I have to hide it. I didn't tell him I was coming here because if I were to tell him he would say, 'Why do you need to go? To waste your time? It's late, you are going to cause an accident, don't go.' So I learned not to tell him stuff, I can't tell him a lot of stuff because then it becomes a problem.

Other women in the focus group confirmed their partners were machistas; their disapproval also made it hard for these women to leave their homes to participate in the research.

Geography and insider/outsider status as barriers to engagement. Participants often described Latino immigrants living in the ECV as isolated and distant from the western Coachella Valley. One participant expressed this existing division within the valley in their comment: "In the western Coachella Valley you find all the rich people, and we, the poor, are left here." The western Coachella Valley was often characterized by participants as affluent, touristic, privileged, and economically developed whereas the eastern side was characterized as poor and lacking resources. The ECV is geographically as well as financially disconnected from the western Coachella Valley, which has contributed to a sense of "insider" (of the community) and "outsider" (not of the community) status.

This status differentiation shaped the community's engagement in research during the 
early stages of the project. It was brought to our attention during unstructured interviews that our university affiliation and physical distance from the ECV placed us as "strangers" and therefore outsiders. This point was further elaborated on during the CRB. Participants indicated the study team's status as "outsiders," (embodied by our race/ethnicity, gender, legal status, and position as researchers), created a significant barrier to engaging the community in the project. One participant in the CRB demonstrated community perceptions of research when she said:

They are going to think, 'More people coming and giving me another survey.' But if someone from the community, someone who has their respect, someone who has a connection with them, they will have that touch to talk to them and they will open up and share their experiences. But if it is with a stranger, they are not going to talk. But if it is someone from the community, they are going to open up freely. They are going to trust them.

This comment demonstrates a preference for research done by respected and trustworthy community members. Yet, as the conversation progressed, participants also shared the complexities of having an insider conduct the research. They addressed concerns that, due to their status as members of the community and their knowledge and relationships with others in the community, researchers might not be as careful and people's anonymity could be inadvertently compromised.

Participants stressed their desire for someone who was familiar with the community, but not necessarily a resident from the area, to conduct the research. The best fit, they felt, was an insider, but being an insider of the community means researcher participation must be nuanced. "Community" in this context not only referred to someone from the physical community, but also to someone with a connection to the immigrant experience. During an unstructured interview with the male research assistant, a man said: "If you're from Mexico, then I'm from Mexico." He expanded on this, explaining that, even if the researcher were from Mexico and some of the participants were from El Salvador, the researcher was trustworthy because they shared an immigrant experience.

Importantly, we found the notion of insider vs outsider status applied to the research team and participants equally. This status plays out in CBPR when multiple voices with diverse backgrounds are engaged in the same discussion. During the Community Review Board, the only male farmworker to attend remained silent throughout the discussion. However, at the end of the discussion, he explained his silence and non-participation with the research team: he feared he could not contribute to the project adequately because he was surrounded by community leaders, service providers, farmworker advocates, and researchers. He perceived himself as an outsider in this group, as he had limited education and lower community involvement, and these perceived factors silenced his voice.

Positionality as a Barrier to Engagement. In conversations with residents of the ECV, undocumented legal status was a recurring theme that prevented many from engaging in research. Advocates and service providers frequently reminded of us these barriers. A farmworkers advocate stated, "One of the main problems is they don't have documentation. You have a lot of people without documentation." During focus group discussions with female farmworkers and their advocates, participants reiterated this point. One participant commented: "Not everyone has documents, there is no access to healthcare or transportation." This participant and others also pointed out that many live in daily fear of deportation. "Men fear border patrol and many that are undocumented don't leave their community."

Such statements drive home the need for researchers to come into the community, instead 
of participants coming out to meet us. They also show the importance of a safe research environment: most of the community members were recent immigrants to the US, and many were afraid to participate in research. Because of their legal status, confidentiality was a significant concern. This was apparent during the consent process prior to the start of the research, where participants expressed concern over audio recordings, the written consent form, and potential name disclosure.

\section{Few Community Resources and Poor} Infrastructure as Barriers to Engagement. Many of the ECV residents in our study lived in unincorporated communities where there are few, if any, public resources, community-based organizations, or service agencies. Consequently, we found it challenging to find public spaces to hold research activities, especially group interviews. This was especially difficult for the focus group with men. We had a hard time finding a location within their communities where they felt safe to attend (e.g., their anonymity was protected and they felt secure accessing the venue). A lack of nearby public facilities created a barrier because participants had to ride-share and travel over 20 miles to the location where the focus group was held. Several men who had initially committed to participating in the focus group decided the travel distance was too great and, in the end, did not participate in the research.

Poor Transportation Infrastructure. These unincorporated communities are also characterized by poor infrastructure (e.g., roads are un- or poorly paved, and there is limited or no access to public transportation). Limited public transportation was frequently discussed as a major barrier to travel between communities and within and outside of the ECV. During the focus group with women farmworkers and their advocates participants discussed travel distance and safety as barriers to travelling outside their communities. One participant commented:
The transportation is limited in this rural area. The lighting is poor. There are many places that need more lighting because the areas where you walk are isolated and there is nothing. The distances [to walk] are great to access public transportation.

This lack of public transportation and limited access to personal cars created significant barriers to engaging both men and women in focus group discussions. This was evident when we scheduled a focus group during the winter rain. For one of our focus groups with women, deteriorating road conditions exacerbated by rain prevented nearly all focus group participants from traveling from the unincorporated communities to the city of Coachella (a distance of $\sim 10$ to 25 miles) because the roads were flooded.

To successfully engage Latino immigrants in rural communities in substance use research, understanding the local historical and cultural context and identifying cultural and structurallevel factors such as gender and legal status (Barkin, Schlundt, \& Smith, 2013) is crucial. Because of the marginalized status of Latinos in the ECV, we employed strategies attending to cultural norms and values (e.g., gender interactions), as well as structural and community vulnerabilities. Our results demonstrate the importance of developing a network of trust in order to respectfully access this marginalized and vulnerable population. Researchers working outside their own cultures should discover and address potential barriers, and self-reflection is essential in order to ensure authentic connections are made at a researcherparticipant level (Fryer et al., 2016).

\section{Discussion}

Our study highlights issues (e.g., structural vulnerabilities, gender roles and insider/outsider status) that must be considered when conducting research within small geographically bounded and isolated communities. Even in small 
populations, variation in values and beliefs exist, and researchers will benefit from considering diverse local perspectives. As we found, meaningful community input throughout the research process (e.g., through unstructured interviews and a Community Review Board) can direct the study design to increase the likelihood of successful community participation in research (Burke \& Albert, 2014; Arcury, Austin, Quandt, \& Saavedra, 1999). Ultimately, this approach can lead to community-informed and/or culturally grounded public health interventions.

\section{Limitations}

Our research was part of an engagement study and was exploratory in nature. The small sample size limits generalizability of the findings. However, because we used multiple methods of data collection (i.e., unstructured interviews, a Community Review Board, and focus groups) we were able to triangulate the data for robust results. Additionally, we determined during the research process that the use of focus groups to discuss sexual health with men was not ideal: (1) men may feel uncomfortable talking about sexual health with other men (even if they know the other participants) because the conversation could potentially disclose personal information on sexual health and disease; and (2) group dynamics (e.g. dominant personalities, perceptions of lower status) can disrupt men's comfort in talking openly and honestly about sex and sexual health (Author, 2017). We believe one-on-one interviews may have been more appropriate for this male population, as they allow insurance of anonymity and prevent men from "talking over" other men.

CBPR creates partnerships and coalitions between researchers and communities that help mobilize resources, change relationships among partners, and serve as catalysts to change discussions around health and immigrant participation in research (Fawcett et al., 1995). Civic engagement through research is a powerful vehicle for change that can improve the health of a community and its members.
However, recognizing the challenges of engaging structurally vulnerable immigrant communities in research, and paying attention to power dynamics and cultural nuances, is necessary for research success.

\section{Implications}

Our work has several implications. First, researchers need to examine their own beliefs and understandings related to the community being studied. For instance, the lead author conducted research as both a Mexican immigrant and student researcher. Her position facilitated rapport building with community members and allowed her to perceive the events from an insider perspective. Nevertheless, the initially all-female research team, which included two Euro-American women, represented a major challenge throughout the project as Latino men and their machismo let them believe it is difficult and inappropriate to discuss sexual topics with women.

Second, relationships with community leaders were critical to successful engagement with the ECV farm working community. These partnerships provided a pathway to connect with participants, as well as guidance throughout the project. In order to facilitate connections with potential study participants, we recommend considering the impacts of gender, ethnicity/race, and education of team members as barriers to engaging the intended community. In our case, we realized that to engage Latino men in research on substance use and sexual transmitted disease risk, we needed someone who could directly connect with the potential study participants (in this case, a male with a shared immigrant experience). Considering the positionality of team members is critical in projects intended to form the basis of long-term collaborative partnerships and that do not use traditional ethnographic methods such as longterm field work (which facilitates rapport building) (S. Horton, Zammit, \& Ong, 2016; S. B. Horton, 2016). 
Our work also shows the potential negative effect of power dynamics and the position of the broader community on the creation of strong connectedness of the community and institutions (in our case the university and the ECV). Unequal power dynamics can prevent researchers from building an evidence base to inform healthcare change and future public health care policies that could have a positive health impact on these populations. To effectively address the needs of vulnerable populations (e.g., because of marginalized social statuses such as undocumented immigrants), cooperative research is essential. Trust and cooperation between researchers and community are fundamental in implementing CBPR projects intended to understand how to better serve these communities in order to increase access to capital or resources (Frerichs et al., 2017).

\begin{abstract}
Conclusion
Community engagement and input on health risk behaviors linked to increased substance use among this group of Latino immigrants are needed to develop interventions acceptable to this community. In order to enhance the capability of conducting research in rural communities we needed to be attentive, patient, and mindful of our own positionality. There is a need to build trust with communities and ensure collaborative research is conducted. A research agenda focused on questions that can directly integrate the diversity in this population and in this area, we could create a future line of inquiry examining factors of intersectionality.
\end{abstract}

\section{References}

Albarrán, C. R., \& Nyamathi, A. (2011). HIV and Mexican migrant workers in the United States: a review applying the vulnerable populations conceptual model. The Journal of the Association of Nurses in AIDS Care: JANAC, 22(3). doi: 10.1016/j.jana.2010.08.001

Alvarez, R. A., Vasquez, E., Mayorga, C. C., Feaster, D. J., \& Mitrani, V. B. (2006). Increasing minority research participation through community organization outreach. Western Journal of Nursing Research, 28(5), 541-560; discussion 561-543. doi:10.1177/0193945906287215

Amaro, H., Cortes, D. E., \& Cacari-Stone, L. (2006). Improving Research on Hispanic Drug Abuse: Key Strategies for Policy Makers. Retrieved from http:/www.thenhsn.org/About/docs/FINAL\%20POLICY\%20BRIEF\%20WITH\%20JOSES\%20RECOMMEND ATIONS\%205-30-06LAYOUT.11.pdf

Apostolopoulos, Y., Sonmez, S., Kronenfeld, J., Castillo, E., McLendon, L., \& Smith, D. (2006). STI/HIV risks for Mexican migrant laborers: exploratory ethnographies. Journal of Immigrant and Minority Health, 8(3), 291-302. doi:10.1007/s10903-006-9334-2

Arcury, T. A., Austin, C. K., Quandt, S. A., \& Saavedra, R. (1999). Enhancing community participation in intervention research: farmworkers and agricultural chemicals in North Carolina. Health Eduction \& Behavior, 26(4), 563-578. doi:10.1177/109019819902600412

Barkin, S., Schlundt, D., \& Smith, P. (2013). Community-engaged research perspectives: Then and now. Academic Pediatrics, 13(2), 93-97. doi: https://doi.org/10.1016/j.acap.2012.12.006

Bernard, H. R. (2002). Research methods in anthropology: Qualitative and quantitative methods. Walnut Creek, CA: AltaMira Press.

Bernard, H. R., \& Ryan, G. W. (2010). Analyzing qualitative data: Systematic approaches. Los Angeles: SAGE.

Bickerton, M. E. (2001). Prospects for a bilateral immigration agreement with Mexico: Lessons from the Bracero Program. Texas Law Review, 79(4), 895-919. Retrieved from http://www.nationalaglawcenter.org/wpcontent/uploads/assets/bibarticles/bickerton_bilateral.pdf

Blackwell, M. (2006). Farmworker Women's Organizing and Gendered Grassroots Leadership. UCLA: Center for the Study of Women. Retrieved from https://escholarship.org/uc/item/9bq9k752 
Bourgois, P., \& Hart, L. K. (2011). Commentary on Genberg et al. (2011): The structural vulnerability imposed by hyper-segregated US inner-city neighborhoods--a theoretical and practical challenge for substance abuse research. Addiction, 106(11), 1975-1977. doi:10.1111/j.1360-0443.2011.03615.x

Burke, J. G., \& Albert, S. M. (2014). Methods for community public health research: Integrated and engaged approaches. Retrieved from http://public.eblib.com/choice/publicfullrecord.aspx?p=1637291

Calderón, J. L., Baker, R. S., Fabrega, H., Conde, J. G., Hays, R. D., Fleming, E., \& Norris, K. (2006). An ethno-medical perspective on research participation: A qualitative pilot study. Medscape General Medicine, 8(2), 23. Retrieved from https://www.ncbi.nlm.nih.gov/pmc/articles/PMC1785211/

Chen, N. E., Gallant, J. E., \& Page, K. R. (2012). A systematic review of HIV/AIDS survival and delayed diagnosis among Hispanics in the United States. Journal of Immigrant and Minority Health, 14(1), 65-81. doi: 10.1007/s10903-011-9497-y

Cheney, A. M., Newkirk, C., Rodriguez, K.*, and Montez, A.* (2018). Inequality and Health among ForeignBorn Latinos in Rural Borderland Communities. Social Science \& Medicine, 215, 115-122. doi: 10.1016/i.socscimed.2018.09.011

Colletti, J., Smith, D., Herrera, S., Herrera, T., \& Flores, L. (2006). Coachella Valley farm worker survey: Final Report. Retrieved from Pasadena, CA: http://www.iurd.org/images/iurd_homepage_doc/Farm_Worker_Survey_CoachellaValley06.pdf

Cohen, D., (2011). Braceros: Migrant Citizens and Transnational Subjects in the Postwar United States and Mexico. The University of North Carolina Press, Chapel Hill, NC.

Corbie-Smith, G., Thomas, S. B., \& St George, D. M. (2002). Distrust, race, and research. Archives of Internal Medicine, 162(21), 2458-2463. doi:10.1001/archinte.162.21.2458

Corbin, J. M., \& Strauss, A. L. (2015). Basics of qualitative research: Techniques and procedures for developing grounded theory. Los Angeles: SAGE.

de Jesus Diaz-Perez, M., Farley, T., \& Cabanis, C. M. (2004). A program to improve access to health care among Mexican immigrants in rural Colorado. The Journal of Rural Health, 20(3), 258-264. Retrieved from https://www.ncbi.nlm.nih.gov/pubmed/15298101

Deren, S., Shedlin, M., Decena, C. U., \& Mino, M. (2005). Research challenges to the study of HIV/AIDS among migrant and immigrant Hispanic populations in the United States. Journal of Urban Health: Bulletin of the New York Academy of Medicine, 82(2), 13-25. doi: 10.1093/jurban/jti060

Du Bry T., (2007). Immigrants, Settlers, and Laborers: The Socioeconomic Transformation of a Farming Community. LFB Scholarly Publishing, New York, NY

Fawcett, S. B., Paine-Andrews, A., Francisco, V. T., Schultz, J. A., Richter, K. P., Lewis, R. K., . . . et al. (1995). Using empowerment theory in collaborative partnerships for community health and development. American Journal of Community Psychology, 23(5), 677-697. Retrieved from https://www.ncbi.nlm.nih.gov/pubmed/8851345

Fielding, N. (2004). Getting the most from archived qualitative data: Epistemological, practical and professional obstacles. International Journal of Social Research Methodology, 7(1), 97-104. doi:10.1080/13645570310001640699

Frerichs, L., Kim, M., Dave, G., Cheney, A., Hassmiller Lich, K., Jones, J., . . Corbie-Smith, G. (2017). Stakeholder perspectives on creating and maintaining trust in community-academic research partnerships. Health Eduction \& Behavior, 44(1), 182-191. doi:10.1177/1090198116648291

Fryer, C. S., Passmore, S. R., Maietta, R. C., Petruzzelli, J., Casper, E., Brown, N. A., . . Quinn, 
S. C. (2016). The symbolic value and limitations of racial concordance in minority research engagement. Qualitative Health Research, 26(6), 830-841. doi:10.1177/1049732315575708

Ganann, R. (2013). Opportunities and challenges associated with engaging immigrant women in participatory action research. Journal of Immigrant and Minority Health, 15(2), 341-349.

George, S., Duran, N., \& Norris, K. (2014). A systematic review of barriers and facilitators to minority research participation among African Americans, Latinos, Asian Americans, and Pacific Islanders. American Journal of Public Health, 104(2), 16-31. doi: 10.2105/AJPH.2013.301706

Hansen, E., \& Donohoe, M. (2003). Health issues of migrant and seasonal farmworkers. Journal of Health Care for the Poor and Underserved, 14(2), 153-164. doi: 10.1353/hpu.2010.0790

Hernandez, A., Donovan, V., Grinberg, Y. Y., Obenaus, A., \& Carson, M. J. (2016). Differential detection of impact site versus rotational site injury by magnetic resonance imaging and microglial morphology in an unrestrained mild closed head injury model. Journal of Neurochemistry, 136 Suppl 1, 18-28. doi:10.1111/jnc.13402

Hinton, L., Guo, Z., Hillygus, J., \& Levkoff, S. (2000). Working with culture: A qualitative analysis of barriers to the recruitment of Chinese-American family caregivers for dementia research. Journal of Cross-Cultural Gerontology, 15(2), 119-137. https://doi.org/10.1023/A:1006798316654

Holmes, S. M. (2011). Structural vulnerability and hierarchies of ethnicity and citizenship on the farm. Medical Anthropology, 30(4), 425-449. doi:10.1080/01459740.2011.576728

Horton, S., Zammit, R., \& Ong, B. N. (2016). Community partnerships A public health approach to ageing, death, dying and loss. Compassionate Communities: Case Studies from Britain and Europe, 60-75.

Horton, S. B. (2016). They Leave Their Kidneys in the Fields: Illness, Injury, and Illegality among U.S. Farmworkers. Oakland, CA: University of California Press.

Hussain-Gambles, M., Atkin, K., \& Leese, B. (2004). Why ethnic minority groups are underrepresented in clinical trials: a review of the literature. Health \& Social Care in the Community, 12(5), 382-388. doi: 10.1111/j.1365-2524.2004.00507.x

Israel, B. A., Schulz, A. J., Parker, E. A., \& Becker, A. B. (1998). Review of community-based research: assessing partnership approaches to improve public health. Annual Review of Public Health, 19, 173-202. doi:10.1146/annurev.publhealth.19.1.173

Katigbak, C., Foley, M., Robert, L., \& Hutchinson, M. K. (2016). Experiences and lessons learned in using community-based participatory research to recruit Asian American immigrant research participants. Journal of Nursing Scholarship, 48(2), 210-218. doi: 10.1111/jnu.12194

Kearney, M. H., Murphy, S., Irwin, K., \& Rosenbaum, M. (1995). Salvaging self: A grounded theory of pregnancy on crack cocaine. Nursing Research, 44(4), 208-213. doi:10.1097/00006199199507000-00004

London, J., Greenfield, T., \& Zagofsky, T. (2013). Revealing the invisible Coachella Valley: Putting cumulative environmental vulnerabilities on the map. Retrieved from Davis, CA https://regionalchange.ucdavis.edu/publication/revealing-invisible-coachella-valley-puttingcumulative-environmental-vulnerabilities

Lopez, S. R. (2002). A research agenda to improve the accessibility and quality of mental health care for Latinos. Psychiatric Services, 53(12), 1569-1573. doi:10.1176/appi.ps.53.12.1569

MacQueen, K. M., McLellan, E., Kay, K., \& Milstein, B. (1998). Codebook development for team-based qualitative analysis. Cultural Anthropology, 10(2), 31-36. Retrieved from http://www.cdc.gov/hiv/pdf/library_software_answr_codebook.pdf

Marcelli, E. A., \& Pastor, M. (2015). Unauthorized and Uninsured: Eastern Coachella Valley 
and Riverside County. Retrieved from San Diego, CA

https://dornsife.usc.edu/assets/sites/731/docs/Web_02_East_Coachella_Riverside_County_Final2 .pdf

Minkler, M., \& Wallerstein, N. (2008). Community-based participatory research for health: from process to outcomes (2nd ed.). San Francisco, CA: Jossey-Bass.

Mitchell, D. (2007). Work, struggle, death, and geographies of justice: The transformation of landscape in and beyond California's Imperial Valley. Landscape Research, 32(5), 559-

577. https://doi.org/10.1080/01426390701552704

National Center for Farmworker Health. (2017). National Center for Farmworker Health. Retrieved from www.ncfh.org

Olson, M., Cottoms, N., \& Sullivan, G. (2015). Engaging underrepresented minorities in research: Our vision for a "Research-Friendly Community". Progress in Community Health Partnerships, 9(4), 595-598. doi:10.1353/cpr.2015.0073

Quesada, J., Hart, L. K., \& Bourgois, P. (2011). Structural vulnerability and health: Latino migrant laborers in the United States. Medical Anthropology, 30(4), 339-362. doi:10.1080/01459740.2011.576725

Saenz, R. (2008). A profile of Latinos in rural America. Fact Sheet No. 10, Winter 2008. Carsey Institute. Retrieved from https://scholars.unh.edu/cgi/viewcontent.cgi?article $=1034 \&$ context=carsey

Sheikh, A., Halani, L., Bhopal, R. S., \& Car, J. (2009). Facilitating the recruitment of minority ethnic people into research: Qualitative case study of South Asians and asthma. PLoS Medicine(6), 1-10. doi.org/10.1371/journal.pmed.1000148

Tapp, H., White, L., Steuerwald, M., \& Dulin, M. (2013). Use of community-based participatory research in primary care to improve healthcare outcomes and disparities in care. Journal of Comparative Effectiveness Research, 2(4), 405-419. doi:10.2217/Cer.13.45

Tate, J. A., Devito Dabbs, A., Hoffman, L. A., Milbrandt, E., \& Happ, M. B. (2012). Anxiety and agitation in mechanically ventilated patients. Qualitative Health Research, 22(2), 157-173. doi:10.1177/1049732311421616

The Housing Assistance Council. (2012). Rural Research Brief: Race \& Ethnicity in Rural America. Retrieved from http://www.ruralhome.org/storage/research_notes/rrn-race-andethnicity-web.pdf

UyBico, S. J., Pavel, S., \& Gross, C. P. (2007). Recruiting vulnerable populations into research: A systematic review of recruitment interventions. Journal of General Internal Medicine, 22(6), 852-863. doi: 10.1007/s11606-007-0126-3

Valverde, E. E., Painter, T., Heffelfinger, J. D., Schulden, J. D., Chavez, P., \& DiNenno, E. A. (2015). Migration patterns and characteristics of sexual partners associated with unprotected sexual intercourse among Hispanic immigrant and migrant women in the United States. Journal of Immigrant and Minority Health, 17(6), 1826-1833. doi: 10.1007/s10903-014-0132-6.

Vanderbilt University Medical Center. (2017). Meharry-Vanderbilt Community Engaged Research Core. Retrieved from http:/victr.vanderbilt.edu/pub/community/

Verbi Software-Consult. (2016). MAXQDA software for qualitative data analysis, 1989-2016. Retrieved from http://www.maxqda.com/

Waheed, W., Hughes-Morley, A., Woodham, A., Allen, G., \& Bower, P. (2015). Overcoming barriers to recruiting ethnic minorities to mental health research: a typology of recruitment strategies. BMC Psychiatry, 15, 101. doi:10.1186/s12888-015-0484-z

Williams, D. R., Mohammed, S. A., Leavell, J., \& Collins, C. (2010). Race, socioeconomic status, and health: Complexities, ongoing challenges, and research opportunities. NYAS Annals of the New York Academy of Sciences, 1186(1), 69-101. doi: 10.1111/j.1749-6632.2009.05339.x. 


\section{Acknowledgements}

At the time of the study, the corresponding author was a Scholar with the HIV/AIDS, Substance Abuse, and Trauma Training Program (HA-STTP) at the University of California, Los Angeles supported through an award from the National Institute on Drug Abuse (R25 DA035692). The authors would like to thank [anonymous] for her editorial support. The project was supported by NIDA pilot funds and a University of California Institute for Mexico and the United States Faculty Small Grant.

Corresponding Author Information

Ann Cheney (ORCID: 0000-0002-4032-6692)

Associate Professor, Department of Social Medicine

Population and Public Health

University of California, Riverside

3333 14th St., Riverside, CA 92501

Tel: 951-715-2713

Email: ann.cheney@medsch.ucr.edu 